\title{
Investigation of in vitro anti-hyperpigmentation, antidiabetic, neuroprotective and antioxidant potential of Medicago murex Willd. (Fabaceae)
}

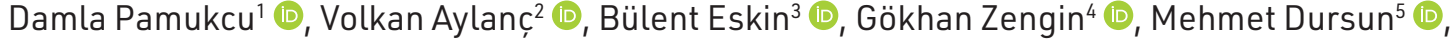 \\ Yavuz Selim Çakmak ${ }^{6}$ (D) \\ ${ }^{1}$ Aksaray University, Faculty of Science and Arts, Department of Biotechnology and Molecular, Aksaray, Turkey \\ ${ }^{2}$ Centro de Investigação de Montanha (CIMO), Instituto Politécnico de Bragança, Bragança, Portugal \\ ${ }^{3}$ Aksaray University, Faculty of Science and Arts, Department of Biotechnology and Molecular, Aksaray, Turkey \\ 4Selcuk University, Faculty of Science, Department of Biology, Konya, Turkey \\ ${ }^{5}$ Montana State University, Collage of Letter and Science, Department of Microbiology and Immunology, Bozeman \\ Montana, USA \\ ${ }^{6}$ Aksaray University, Faculty of Science and Arts, Department of Biotechnology and Molecular, Aksaray, Turkey
}

ORCID IDs of the authors: D.P. 0000-0001-5819-7449; V.A. 0000-0003-4060-766X; B.E. 0000-0002-7990-4138; G.Z. 0000-0001-6548-7823; M.D. 0000-0002-8214-4942; Y.S.C.. 0000-0001-8954-5485

Cite this article as: Pamukcu, D., Aylanc, V., Eskin, B., Zengin, G., Dursun, M., \& Çakmak, Y. S. (2020). Investigation of in vitro antihyperpigmentation, antidiabetic, neuroprotective and antioxidant potential of Medicago murex Willd. (Fabaceae). Istanbul Journal of Pharmacy, 50 (3), 289-293.

\section{ABSTRACT}

Background and Aims: Most of the Medicago species are considered good quality forage crops due to their rich protein content. This study reports antioxidant properties, total phenolic and flavonoid content, enzyme (acetylcholinesterase (AChE), tyrosinase, $\alpha$-amylase and $\alpha$-glucosidase) inhibition activities of methanol ( $\mathrm{MeOH}$ ), ethyl acetate (EA) and, aqueous (AQ) extracts of Medicago murex (M. murex).

Methods: The antioxidant activity of the different extracts of $M$. murex were evaluated using FRAP and CUPRAC assays. The contents of total phenolic and flavonoid were determined by the Folin-Ciocalteu and the Aluminium chloride ( $\mathrm{AlCl}_{3}$ ) colorimetric methods. Also, the enzyme inhibition activities were shown spectrophotometrically for AChE, $\alpha$-amylase, $\alpha$-glucosidase and tyrosinase enzymes.

Results: Total phenolic and flavonoid contents of different extracts were determined between 83.70-163.93 mg GAE/g extract and 24.48-26.05 $\mu \mathrm{g} Q \mathrm{E} / \mathrm{g}$ extract, respectively. $A Q$ extracts were the most active extracts in FRAP while being the best inhibitor of the AChE enzyme. On the other hand, EA extracts were the most active extracts in CUPRAC methods and the best inhibitors for other enzymes.

Conclusion: Considering the findings, M. murex appears to be an important source of natural antioxidants and enzyme inhibitors, and it provides important baseline data for the food and pharmaceutical industries.

Keywords: M. murex, bioactive substances content, antioxidant potential, enzyme inhibition 


\section{INTRODUCTION}

Plants have been used for therapeutic purposes throughout history. There has been an increasing interest in bioactive compounds from the plant kingdom recently because they have fewer side effects, are cheaper than general synthetic drugs, and influence the production of free radicals (Martins, Barros \& Ferreira, 2016). Apart from these facts, bioactive compounds have been reported to have protecting effects against extensive dietary-related diseases, including cancer, obesity, cardiovascular diseases, diabetes and various inflammatory conditions (Quideau, Deffieux, Douat-Casassus, \& Pouységu, 2011).

Medicago spp., a member of the family Fabaceae, is one of the important forage plants around the world with economic value and includes 87 flowering plant species, some of which are consumed by humans (Gholami, De Geyter, Pollier, Goormachtig \& Goossens, 2014). Medicago species synthesize various natural bioactive products to maintain symbiotic interactions and at the same time to deter pathogens and herbivores (Ghimire, Ghimire, Yu, \& Chung , 2019). These products are most of the time natural bioactive compounds with a functional nutrient source and promising pharmaceutical properties for humans. Medicago species are traditionally consumed as salads, sandwiches, soups and tisane (Takyi, Kido, Rikimaru, \& Kennedy, 1992), and also its leaves are used to reduce cholesterol level (Mölgaard, von Schenck, \& Olsson, 1987). Despite these uses, Medicago spp. has been practiced in health problems, including diabetes, gastric ulcer, cancer and menopause symptoms due to its different therapeutic effects (Mortensen et al., 2009).

Medicago spp. contain bioactive compounds like flavonoids, ligands, carotenoids and phenolic acids that have beneficial effects on health (Xu et al., 2017). Especially are a major group of phenolic compounds and there is a great interest in these compounds because of their strong antioxidant activity against oxidative stress. Recently, some studies have identified the relationship between these compounds and cancer risk (Sudhakaran, Sardesai, \& Doseff, 2019).

M. murex is a member of the Medicago genus and is an annual legume of Mediterranean origin, usually grown in acidic soils. It is also an important grazing plant that is commonly seen in the pastures and is widely distributed from the Mediterranean to Central Asia (Francis \& Gillespie, 1981). Studies on Medicago spp. generally focus on Alfalfa (Medicago sativa L.). Other Medicago species, including M. murex have been ignored. The studies on $M$. murex are generally limited to molecular cytogenetics, phylogenetics, morphology and geographical distribution (Gillespie \& McComb, 1991). In this study, M. murex plant was chosen as a bioactive compound source for the following reasons; i) easy cultivation, ii) worldwide distribution, and iii) used as a functional food in different countries. This research is the first study to reveal the therapeutic properties of $M$. murex such as anti-hyperpigmentation, antidiabetic, neuroprotective and antioxidant. The aim of this study was to investigate the antioxidant properties, enzyme inhibition activities and phenolic composition of different extracts of $M$. murex and to evaluate the potential of this species for food and pharmacology industries.

\section{MATERIALS AND METHODS}

\section{Plant material}

Aerial parts of M. murex were collected from Kargin Village (Aksaray-Turkey) in the vegetation period in February 2015 and were identified by botanist experts, Assist. Prof. Dr. Bulent Eskin and Dr. Mustafa Keskin. A voucher specimen (No. (AKSU) BE-2226) has been deposited at Aksaray University Herbarium, Turkey.

\section{Preparation of extracts}

For the extraction process of plant samples, the aerial parts of M. murex samples were dried at room temperature and weighed at $15 \mathrm{~g}$ each in order to make $\mathrm{MeOH}, \mathrm{EA}$ and $\mathrm{AQ}$ extracts. $\mathrm{MeOH}$ and EA extracts were subjected to extraction using a Soxhlet apparatus for 6-8 h. AQ extract was carried out by steeping in boiling water for 30 min. After that, the extracts were filtered and evaporated. Total yields of dried samples were calculated and stored at $-20{ }^{\circ} \mathrm{C}$ until analysis. Stock solutions were prepared from these extracts at a concentration of $2 \mathrm{mg} / \mathrm{mL}$ prior to analysis.

\section{Profile of bioactive compounds}

The content of two major groups of bioactives; phenols (TPC) and flavonoids (TFC) in obtained extracts was determined by using spectrophotometric methods. Expression of obtained results was done by equivalents of standards - gallic acid (TPC) and quercetin (TFC) (Uysal et al., 2017).

\section{Determination of enzyme inhibition and antioxidant activity}

The polarity and chemical properties of different solvents are known to affect the solubility of bioactive compounds. Therefore, solvents with different polarities ( $\mathrm{AQ}$ (high polarity) $>\mathrm{MeOH}$ (less polar than $\mathrm{AQ}$ ) > EA (moderately polar) were preferred. Potential biological activities of the obtained extracts with different solvents were performed: antioxidant, anti-a-amylase, antia -glucosidase, anti-AChE and anti-tyrosinase activity assays. Estimation of anti-enzymatic activity of the extracts was done by in vitro assays previously described by Uysal et al. (2017). The enzyme inhibitory actions of extracts were assessed as equivalents of kojic acid (KAE) for tyrosinase, galantamine for AChE and acarbose for a-amylase and a- glucosidase.

Antioxidant activity of different extracts was measured by ferric ion reducing antioxidant power (FRAP) and cupric ion reducing antioxidant capacity (CUPRAC) assays. Detailed description of applied assays were given previously (Uysal et al., 2017). The findings were given as standard compounds equivalent of Trolox (TE/g). The assay methods were given in our earlier work.

\section{Statistical analysis}

All analyses were performed in triplicate and the obtained results were expressed as mean \pm standard deviation (SD). The obtained data was analysed using SPPS 26 software (Chicago, IL, USA). One-way analysis of variance was conducted to see whether there is a statistical significance. $p<0.05$ was considered as significant.

\section{RESULTS AND DISCUSSION}

\section{Total phenolic and flavonoid content}

Phenol or polyphenol substances can be defined as chemical plant components containing a phenolic ring in structure. Ac- 
cording to the results given in Table 1, the TPC of the extracts of the plant were found to vary between 83.70 and $163.93 \mathrm{mg}$ GAE/g extract. The highest phenolic content was seen in AQ extract followed by $\mathrm{MeOH}$ and EA extract. In previous studies on Medicago species Kicel \& Olszewska (2015) showed that the TPC of different fractions obtained from M. lupilina were between 6.6 and 162.4 mg GAE and, while Çakmak et al. (2017) found the TPC of M. rigidula as $79.61 \mathrm{mg}$ GAE. Based on the studies reported in the literature, different or same Medicago species may have different rates of phenolic substance content depending on different factors such as geographical area, climate or genetics (Baiano, Terracone, Viggiani, \& Del Nobile, 2013).

The TFC of three different extracts of $M$. murex was determined by using the $\mathrm{AlCl}_{3}$ colorimetric method. As stated in Table 1; the highest TFC was found in $\mathrm{MeOH}$ extract (26.05 $\mu \mathrm{g}$ QE/g) and also no flavonoid content was detected in EA extract. This may be due to the flavonoid compounds with different chemical properties and polarities that can be dissolved or insoluble in the $M$. murex plant in moderately polar solvents like EA. Besides, parameters such as the type of plant, the chemical nature of the extractable bioactive compounds and the solubilizing effect of solvents may affect the obtaining of phenolics from extracts (Adaramola \& Onigbinde, 2016).

In a study on M. rigidula, the TFC of the plant was $27.38 \mu \mathrm{g} Q \mathrm{QE} / \mathrm{g}$ extract (Çakmak et al., 2017). Rodrigues et al. (2013) investigated the TPC and TFC of some Medicago species and found that TFC ranged from 5.54 to $11.67 \mathrm{mg}$ CEQ/g db. In the present study, considering the TFC being found in different extracts, one could conclude that $M$. murex contains a good amount of flavonoids. Besides that, no statistically significant correlation was found between TPC and TFC in the statistical analysis performed.

\section{Antioxidant activity}

In the present study, the FRAP results of the different extracts obtained from $M$. murex are given in Table 1 as equivalent to Trolox. The iron-reducing antioxidant power of extracts was found quite close to each other, and for $\mathrm{MeOH}, \mathrm{EA}$ and $\mathrm{AQ}$ were measured as 81.94, 85.81 and $91.41 \mathrm{mg} \mathrm{TE} / \mathrm{g}$, respectively. A previously reported study, FRAP test was applied to the $\mathrm{MeOH}$ extract of $\mathrm{M}$. lupulina, and it was observed that $\mathrm{MeOH}$ extract had $0.2 \mathrm{mmol} \mathrm{Fe}^{+2} / \mathrm{g}$ dry extract activity but when Trolox and quercetin used as a standard were found as 9.2 and $36.70 .2 \mathrm{mmol} \mathrm{Fe}+2 / \mathrm{g}$ dry extract activity (Kicel \& Olszewska,

Table 1. The TPC, TFC and FRAP activity of different extracts obtained from M. murex.

\begin{tabular}{|c|c|c|c|c|}
\hline Extr & $\begin{array}{c}\text { Yield } \\
(\%)\end{array}$ & $\begin{array}{c}\text { TPC }^{\mathrm{a}} \\
\text { (mg GAE/g) }\end{array}$ & $\begin{array}{c}T_{F C^{b}} \\
(\mu g Q E / g)\end{array}$ & $\begin{array}{c}\text { FRAPc }^{(} \\
(\mathrm{mg} \mathrm{TE} / \mathrm{g})\end{array}$ \\
\hline $\mathrm{MeOH}$ & 12.09 & $95.98 \pm 0.64^{*}$ & $26.05 \pm 2.16$ & $81.94 \pm 1.74$ \\
\hline EA & 3.77 & $83.70 \pm 3.36$ & - & $85.81 \pm 0.05$ \\
\hline$A Q$ & 11.80 & $163.93 \pm 0.64$ & $24.48 \pm 0.35$ & $91.41 \pm 2.22$ \\
\hline
\end{tabular}

a TPC expressed as gallic acid equivalent (mg GAE g-1 extract);

b TFC expressed as quercetin equivalents ( $\mu \mathrm{g} Q \mathrm{QE} \mathrm{g}^{-1}$ extract);

c FRAP expressed as trolox equivalents (mg TE g ${ }^{-1}$ extract); ${ }^{*}$ Values

expressed are means \pm S.D. of three parallel measurements.
2015). In another study investigating different Medicago species, the highest FRAP activity (with $120.84 \mu \mathrm{mol}$ TE/g) was determined in M. segitalis, while the lowest FRAP activity (with $58.05 \mu \mathrm{mol} / \mathrm{g}$ ) was determined in M. minima (Rodrigues et al., 2013). Also, a correlation analysis was conducted between FRAP and TPC/TFC of $M$. murex extracts in this study. Based on the obtained results, there is a strong correlation between FRAP and TPC and TFC. In the previously reported studies, it was mentioned that there is a correlation between total phenolic and flavonoid substance and FRAP (Babbar, Oberoi, Uppal, \& Patil, 2011).

The results of the applied CUPRAC test to determine the reducing power of copper ions are given in Figure 1. Accordingly, at the highest concentration $(400 \mu \mathrm{g} / \mathrm{mL})$, the EA extract had an absorbance of $0.510 \mathrm{abs}$, followed by $\mathrm{MeOH}(0.358 \mathrm{abs})$ and AQ extract (0.313 abs). In a study on M. rigidula, it was found that the absorbance values vary between 0.058 to 0.733 in the same concentration range $(50,100,200$ and $400 \mu \mathrm{g} / \mathrm{ml})$ (Çakmak et al., 2017). There was a correlation between TPC and CUPRAC in our study based on the statistical evaluation of obtained results, as some authors have previously stated (Fidrianny, Budiana, \& Ruslan, 2015). Besides, a strong correlation was determined between TFC and CUPRAC, and it was observed that the correlation coefficient decreased when copper ions concentration increases: $r=0.997, r=0,424, r=0,321$ and $r=$ 0,218 correlation coefficients were obtained for 50, 100, 200 and 400 of CUPRAC concentrations, respectively.

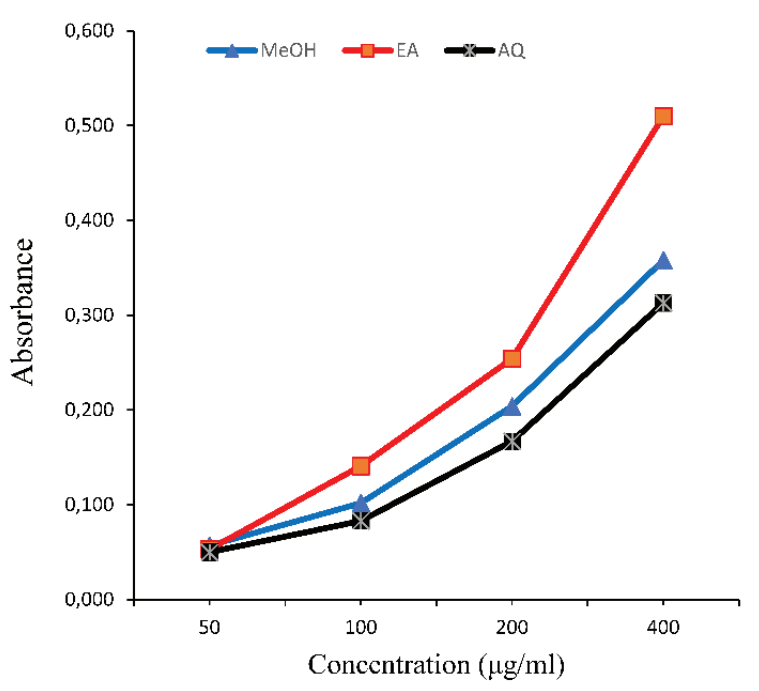

Figure 1. Cupric ion reducing power activity of M. murex.

\section{Enzyme inhibitory effects}

Metabolic diseases are among the most common diseases, especially diabetes, Alzheimer's disease (AD) or skin pigmentation disorders and enzyme inhibition studies are a novel and up-to-date alternative in the treatment of these diseases (Zengin et al., 2019). Therefore, potential enzyme inhibitor research of phytochemicals in plants is becoming more common. In this study, MeOH, EA and AQ extracts of $M$. murex were 
Table 2. Enzyme inhibitory potentials of M. murex.

\begin{tabular}{|lcccc|} 
Extracts & $\begin{array}{c}\text { AChE } \\
\text { Inhibition } \\
\text { (mg GALAE/g extract) }\end{array}$ & $\begin{array}{c}\alpha \text {-Amylase } \\
\text { Inhibition } \\
\text { (mmol ACAE/g extract) }\end{array}$ & $\begin{array}{c}\text { a-Glucosidase } \\
\text { Inhibition } \\
\text { (mmol ACAE/g extract) }\end{array}$ & $\begin{array}{c}\text { Tyrosinase } \\
\text { Inhibition } \\
\text { (mg KAE/g extract) }\end{array}$ \\
\hline $\mathrm{MeOH}$ & $1.84 \pm 0.06$ & $0.82 \pm 0.03$ & $4.28 \pm 0.31$ & $17.92 \pm 0.18$ \\
$\mathrm{EA}$ & $1.17 \pm 0.14$ & $1.01 \pm 0.02$ & $6.34 \pm 0.17$ & $28.29 \pm 1.02$ \\
$\mathrm{AQ}$ & $2.02 \pm 0.16$ & $0.41 \pm 0.02$ & $2.70 \pm 0.16$ & $4.23 \pm 0.56$ \\
\hline $\begin{array}{l}\text { Values expressed are means } \\
\text { acid equivalent. }\end{array}$ & & & \\
\hline
\end{tabular}

investigated to evaluate for potential inhibitory activity against key enzymes related to diabetes, $A D$ and hyperpigmentation problems and the obtained results are given in Table 2.

Control of AD is largely dependent on the inhibition of AChE. The $A C h E$ is the principal therapeutic target in the treatment of $A D$ because of its ability to hydrolyse neurotransmitter acetylcholine. The elevation of AChE causes acetylcholine deficiency in the brain and hence, inhibition of AChE plays an important role in alleviating the symptoms of AD (Hassan, Raza, Abbasi, Moustafa, \& Seo, 2019). Based on our findings, the highest activity in AChE enzyme inhibition was found in AQ extract (2.02 mg GALAE/g) and the lowest value was found in EA extract (1.17 mg GALAE/g). Also, all three extracts were found to be active against AChE.

The a-amylase and a-glucosidase enzymes, which are effective on glucose metabolism, showed inhibition activity as 1.01 $\mathrm{mmol}$ ACAE/g and $6.34 \mathrm{mmol}$ ACAE/g extract, respectively, and the highest ratio was observed in EA extract for both enzymes. a-amylase and a-glucosidase are carbohydrate hydrolysing enzymes and inhibition of both enzymes has a considerable role in the regulation of hyperglycemia. Nowadays, hypoglycemic drugs have many side effects, including gastrointestinal disorders. Excessive a-amylase inhibition has been found to disrupt the normal digestion process and cause different gastrointestinal problems such as bloating, diarrhea, and abdominal pain (Alam, Shafique, Amjad, \& Bin Asad, 2019). While the tested extracts showed a weak activity on the a-amylase enzyme, they showed a moderate activity on the a-glucosidase enzyme. At the same time, a-amylase enzyme inhibition activities were found to be statistically significant $(p<0.05)$ with both TPC and TFC. In a study on the enzyme inhibition in $\mathrm{MeOH}$ extract of $M$. rigidula, AChE, amylase, a-glucosidase and tyrosinase enzyme inhibitions were determined as $2.05 \mathrm{mg} \mathrm{GALAE} / \mathrm{g}, 0.73 \mathrm{mmol}$ ACAE/g, $1.30 \mathrm{mmol} \mathrm{ACAE} / \mathrm{g}$ and $16.36 \mathrm{mg} \mathrm{KAE} / \mathrm{g}$ extract, respectively (Çakmak et al., 2017).

Hyperpigmentation management in today's common diseases is largely dependent on the tyrosinase enzyme, an enzymecontaining copper, and the tyrosinase enzyme also plays an important role in melanin synthesis (Zengin et al., 2019). The use of tyrosinase inhibitors is increasing in the pharmaceutical and cosmetic industries, especially because of their skin whitening and anti-pigmentation effects after sunburn. In the present study, EA extract showed higher tyrosinase inhibitory activity than $\mathrm{MeOH}$ and $\mathrm{AQ}$ extracts (Table 2).

\section{CONCLUSION}

In this study, besides antioxidant and enzyme inhibition activities of M. murex, total phenolic and flavonoid substance contents were also studied. According to the obtained results, the TPC was recorded highest in the AQ extract, while the TFC was recorded in the $\mathrm{MeOH}$ extract. In addition, the FRAP value was found the highest in AQ extract as well as maximum CUPRAC value was recorded in EA extract. All of the extracts of the M. murex plant showed inhibitory activity against all the studied enzymes. Especially a-glucosidase enzyme inhibition has been found to be at high levels compared to the a-amylase enzyme which works together with a-glucosidase in glucose metabolism. High inhibition of a-amylase and a-glucosidase enzymes, especially in EA extract, may be considered as an indicator that the plant has an important potential in the treatment of type 2 diabetes. However, more research is needed to understand the mechanisms and effects of $M$. murex biological activity.

Peer-review: Externally peer-reviewed.

Author Contributions: Conception/Design of Study- D.P., B.E., Y.S.Ç.; Data Acquisition- D.P., V.A., B.E., G.Z., M.D., Y.S.Ç.; Data Analysis/Interpretation- D.P., V.A., G.Z., M.D., Y.S.Ç.; Drafting Manuscript- V.A., G.Z., M.D., Y.S.Ç.; Critical Revision of Manuscript- V.A., G.Z., M.D., Y.S.Ç.; Final Approval and Accountability- D.P., V.A., B.E., G.Z., M.D., Y.S.Ç.; Technical or Material Support- B.E., Y.S.Ç.; Supervision- G.Z., Y.S.Ç.

Conflict of Interest: The authors have no conflict of interest to declare.

Financial Disclosure: Authors declared no financial support.

Acknowledgement: We would like to thank botanist experts Dr Mustafa Keskin for identifying the plant.

\section{REFERENCES}

- $\quad$ Adaramola, B., \& Onigbinde, A. (2016). Effect of extraction solvent on the phenolic content, flavonoid content and antioxidant capacity of clove bud. Article in IOSR Journal of Pharmacy and Biological Sciences, 11(2), 33-38.

- $\quad$ Alam, F., Shafique, Z., Amjad, S. T., \& Bin Asad, M. H. H. (2019). Enzymes inhibitors from natural sources with antidiabetic activity: A review. Phytotherapy Research, 33(1), 41-54.

- Babbar, N., Oberoi, H. S., Uppal, D. S., \& Patil, R. T. (2011). Total phenolic content and antioxidant capacity of extracts obtained from six important fruit residues. Food Research International, 44(1), 391-396. 
- Baiano, A., Terracone, C., Viggiani, I., \& Del Nobile, M. A. (2013). Effects of cultivars and location on quality, phenolic content and antioxidant activity of extra-virgin olive oils. JAOCS, Journal of the American Oil Chemists' Society, 90(1), 103-111.

- Çakmak, Y. S., Zengin, G., Eskin, B., Yıldırım, K., Topal, M., Aydın, G. H. ... Erten, K. (2017). Investigation of Antioxidant and Enzyme Inhibition Activities and Phenolic Compound of Medicago rigidula (L.) All. Marmara Pharmaceutical Journal, 21(3), 522-529.

- Fidrianny, I., Budiana, W., \& Ruslan, K. (2015). Antioxidant activities of various extracts from ardisia sp leaves using dpph and cuprac assays and correlation with total flavonoid, phenolic, carotenoid content. International Journal of Pharmacognosy and Phytochemical Research, 7, 859-865.

- Francis, C. M., \& Gillespie, D. J. (1981). Ecology and distribution of subterranean clover and Medicago species in Sardinia. Australian Plant Introduction Review, 13, 15-25.

- Ghimire, B. K., Ghimire, B., Yu, C. Y., \& Chung, I.-M. (2019). Allelopathic and Autotoxic Effects of Medicago sativa-Derived Allelochemicals. Plants, 8(7), 233.

- Gholami, A., De Geyter, N., Pollier, J., Goormachtig, S., \& Goossens, A. (2014). Natural product biosynthesis in Medicago species. Natural Product Reports, 31(3), 356-380.

- $\quad$ Gillespie, D. J., \& McComb, J. A. (1991). Morphology and distribution of species in the Medicago murex complex. Canadian Journal of Botany, 69(12), 2655-2662.

- Hassan, M., Raza, H., Abbasi, M. A., Moustafa, A. A., \& Seo, S.-Y. (2019). The exploration of novel Alzheimer's therapeutic agents from the pool of FDA approved medicines using drug repositioning, enzyme inhibition and kinetic mechanism approaches. Biomedicine \& Pharmacotherapy, 109, 2513-2526.

- Kicel, A., \& Olszewska, M. A. (2015). Evaluation of antioxidant activity, and quantitative estimation of flavonoids, saponins and phenols in crude extract and dry fractions of Medicago lupulina aerial parts. Natural Product Communications, 10(3), 483-486.

- Martins, N., Barros, L., \& Ferreira, I. C. F. R. (2016). In vivo antioxidant activity of phenolic compounds: Facts and gaps. Trends in Food Science \& Technology, 48, 1-12.
Mölgaard, J., von Schenck, H., \& Olsson, A. G. (1987). Alfalfa seeds lower low density lipoprotein cholesterol and apolipoprotein B concentrations in patients with type II hyperlipoproteinemia. Atherosclerosis, 65(1-2), 173-179.

Mortensen, A., Kulling, S. E., Schwartz, H., Rowland, I., Ruefer, C. E., Rimbach, G., Cassidy, A., Magee, P., Millar, J., \& Hall, W. L. (2009). Analytical and compositional aspects of isoflavones in food and their biological effects. Molecular Nutrition \& Food Research, 53(S2), S266-S309.

- Quideau, S., Deffieux, D., Douat-Casassus, C., \& Pouységu, L. (2011). Plant polyphenols: Chemical properties, biological activities, and synthesis. In Angewandte Chemie - International Edition (pp. 586-621).

- Rodrigues, F., Palmeira-de-Oliveira, A., das Neves, J., Sarmento, B., Amaral, M. H., \& Oliveira, M. B. (2013). Medicago spp. extracts as promising ingredients for skin care products. Industrial Crops and Products, 49, 634-644.

Sudhakaran, M., Sardesai, S., \& Doseff, A. I. (2019). Flavonoids: new frontier for immuno-regulation and breast cancer control. Antioxidants, 8(4), 103.

Takyi, E. E. K., Kido, Y., Rikimaru, T., \& Kennedy, D. O. (1992). Possible use of alfalfa (Medicago sativa) as supplement in infant nutrition: Comparison of weight gained by rats fed on alfalfa and a popular weaning diet. Journal of the Science of Food and Agriculture, 59(1), 109-115.

- Uysal, S., Zengin, G., Locatelli, M., Bahadori, M. B., Mocan, A., Bellagamba, G. ... Aktumsek, A. (2017). Cytotoxic and enzyme inhibitory potential of two potentilla species (P. speciosa L. and P. reptans Willd.) and their chemical composition. Frontiers in Pharmacology, 8, 290.

- $\quad$ Xu, D.-P., Li, Y., Meng, X., Zhou, T., Zhou, Y., Zheng, J., Zhang, J.-J., \& Li, H.-B. (2017). Natural antioxidants in foods and medicinal plants: Extraction, assessment and resources. International Journal of Molecular Sciences, 18(1), 96.

- Zengin, G., Sieniawska, E., Senkardes, I., Picot-Allain, M. C. N., Sinan, K. I., \& Mahomoodally, M. F. (2019). Antioxidant abilities, key enzyme inhibitory potential and phytochemical profile of Tanacetum poteriifolium Grierson. Industrial Crops and Products, 140, 111629. 